\title{
DETECTION OF THIOTHIAMINE IN NATURAL FOODSTUFFS ${ }^{t}$
}

\author{
TAKASHI SUHARA AND NOBUKO IRITANI \\ Tezukayama-Gakuin Junior College, Tezukayama, Sumiyoshi, Osaka
}

(Received January 30, 1962)

Thiothiamine (I), an intermediary product in the industrial synthesis of thiamine, is<smiles>Cc1ncc(Cn2c(C)c(CCO)sc2=S)c(N)n1</smiles>
produced by aeration from an alkaline solution of thiamine. Thiothiamine is converted into thiamine by an oxidant, and a dilute solution of thiothiamine is oxidized into thiamine by the oxygen dissolved in the solution (1). The thiothiamine in natural foodstuffs, if any, may be oxidized to thiamine during zeolite treatment. The existence of thiothiamine in the onion has been proved by Kawasaki and Horio (2) by paper chromatography. Yurugi et al. (3) have reported the formation of thiothiamine by heating the ethanol extract of the onion together with thiamine at $\mathrm{pH} 8$.

The authors have studied the assay method of thiothiamine in onions, especially in the presence of thiamine in order to test the occurrence of thiothiamine in natural foodstuffs.

\section{EXPERIMENTAL}

\section{Preparation of Extract}

Twenty grams of a vegetable was directly or after heating in a boiling waterbath for 5 minutes, homogenized in a glass homogenizer and $1 \mathrm{~N} \mathrm{HCl}$ was added up to $100 \mathrm{ml}$. In all the experiments, the distilled water was boiled to remove free chlorine.

\section{Assay of Thiothiamine}

Benzoyl Peroxide Method-Thiothiamine is oxidized with alkaline benzoyl peroxide solution and the thiochrome thus formed is extracted with isobutanol and determined fluorometrically (3). Under these conditions, no thiamine is produced.

Oxidation with $\mathrm{BrCN}-$-Cyanogen bromide method has also been reported for determining thiothiamine (4), but thiochrome is also produced from thiamine, and the fractionation of both substances is difficult. Kawasaki, Suhara and Horio ${ }^{2}$ have found that thiochrome was converted to thiamine by the reaction with

\footnotetext{
${ }^{1}$ Studies on Thiothiamine. VI. ${ }^{2}$ Unpublished.
} 
cyanogen bromide at an acidic reaction below $\mathrm{pH} 4$, whereas thiamine failed to react with cyanogen bromide under this condition, but reacted after addition of alkali. The reaction of thiothiamine with cyanogen bromide at an acidic reaction is promoted by heating. The authors have adopted the following condition. Three $\mathrm{ml}$ of $3 \% \mathrm{BrCN}$ was added to $1-3 \mathrm{ml}$ of the sample solution ( $\mathrm{pH} 3.4$ ). After standing at $37^{\circ}$ for 30 minutes, the excess $\mathrm{BrCN}$ was removed by aeration, and the thiochrome thus formed was extracted with isobutanol, followed by fluorometric estimation using the solution without $\mathrm{BrCN}$ treatment as the control. Besides this, a recovery test was made by adding $20 \mu \mathrm{g}$ thiothiamine ( $1 \mu \mathrm{g}$ per $\mathrm{g}$ tissue) to the homogenized solution. As shown in Table I, the values determined by benzoyl peroxide method agreed practically with those determined by the above method. Since the values for thiamine remained unchanged after $\mathrm{BrCN}$ treatment, thiamine is considered to remain unchanged by $\mathrm{BrCN}$ treatment.

TABLE I

Comparison of the Values for Thiamine and Thiothiamine in Vegetables

$A$, cold extract of the sample was used directly. Thiamine was determined by ferricyanide method and thiothiamine by benzoyl peroxide method.

$B$, the extract was treated with $\mathrm{BrCN}$ at $\mathrm{pH}$ 3.4. After removal of $\mathrm{BrCN}$, thiamine was determined by ferricyanide method and thiothiamine was determined from the thiochrome formed by $\mathrm{BrCN}$ treatment.

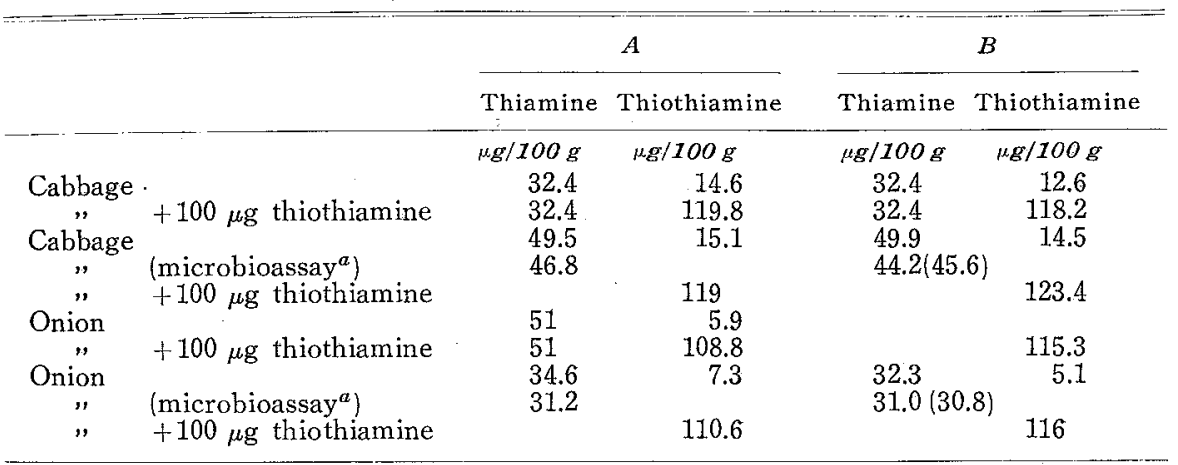

${ }^{a}$ With L. fermenti.

The parenthesized figures represent the values of the extract after $\mathrm{BrCN}$ treatment without aeration.

In the recovery test of thiothiamine, the solution reacted with $\mathrm{BrCN}$ for 30 minutes showed spectrophotometrically the absorption maximum at $360 \mathrm{~m} \mu$, specific for thiochrome and the value of $E_{1 \% \mathrm{~cm}}^{1 \%}$ rose by 0.01 after addition of $100 \mu \mathrm{g}$ thiothiamine per $100 \mathrm{ml}$.

Microbiological Assay_ Thiothiamine cannot be determined with Lactobacillus fermenti. However, it can be assayed after conversion of thiothiamine to thiamine as follows.

Sulfurous acid water (containing $24.1 \mathrm{mg} \mathrm{SO}$ ), $1 \mathrm{ml}$, was added to $50 \mathrm{ml}$ of the solution under test, and the $\mathrm{pH}$ was adjusted to 4.5 . The solution was filled with water up to $100 \mathrm{ml}$, followed by incubation at $38^{\circ}$ overnight. The excess sulfurous acid was removed by aeration at $\mathrm{pH} 1$ until no blue reaction was observed on an 
iodine-starch paper. The thiamine thus formed is determined by the conventional microbioassay technique using l. fermenti. The value for thiothiamine was calculated by subtracting the value of the untreated solution from that of the tested. Thiamine was shown not to be decomposed by this treatment; $100 \mathrm{ml}$ of the solution containing 15 or $20 \mu \mathrm{g}$ thiamine was treated with sulfurous acid and 100 , of the added thiamine was recovered. The values obtained by this method agreed well with those obtained by benzoyl peroxide method using the cold extract of onions. Following figures were obtained in the case of onions (parenthesized figures represent the values obtained by benzoyl peroxide method): 15 (15), 13 (15), 19 (18), 17 (18), 18 (20), 16 (14), 18 (29), 18 (20), 18 (28), 13 (13), 1:3 (11), 40 (29), 15 (16), 20 (29), 15 (15); average standard deviation was $19 \cdot 7(19 \cdot 6)$.

\section{Assay of Thiamine and Thiothiamine in () nions:}

Each $20 \mathrm{~g}$ was taken from both the external and internal parts of an onion and the cold extracts were prepared. The thiamine and thiothiamine values of the extracts were determined with and without zeolite treatment with the results as shown in Table II. Thiamine was assayed by both ferricyanide method and microbiological method using L.fermenti, whereas thiothiamine by both benzoyl peroxide method and microbiological method. Thiamine values of the onion determined by ferricyanide method were $38 \mu \mathrm{g} 100 \mathrm{~g}$ in the interior part and $17 \mu \mathrm{g} 100 \mathrm{~g}$ in the interior part, whereas those by microbioassay 42 and $24 \mu \mathrm{g} 100 \mathrm{~g}$ respectively. Both values agreed pretty well. Thiothiamine values determined by benzoyl peroxide method were $23 \mu \mathrm{g}, 100 \mathrm{~g}$ in the interior part and $19 \mu \mathrm{g} / 100 \mathrm{~g}$ in the exterior part. Both values agreed pretty well with those determined by microbioassay. Considering only the cases with zeolite treatment, the thiamine values obtained by zeolite treatment were, in both chemical and microbiological assays, higher and the thiothiamine values lower than

TABLE II

Thiamine and 'Thiothiamine Content in Onions:

Interior part

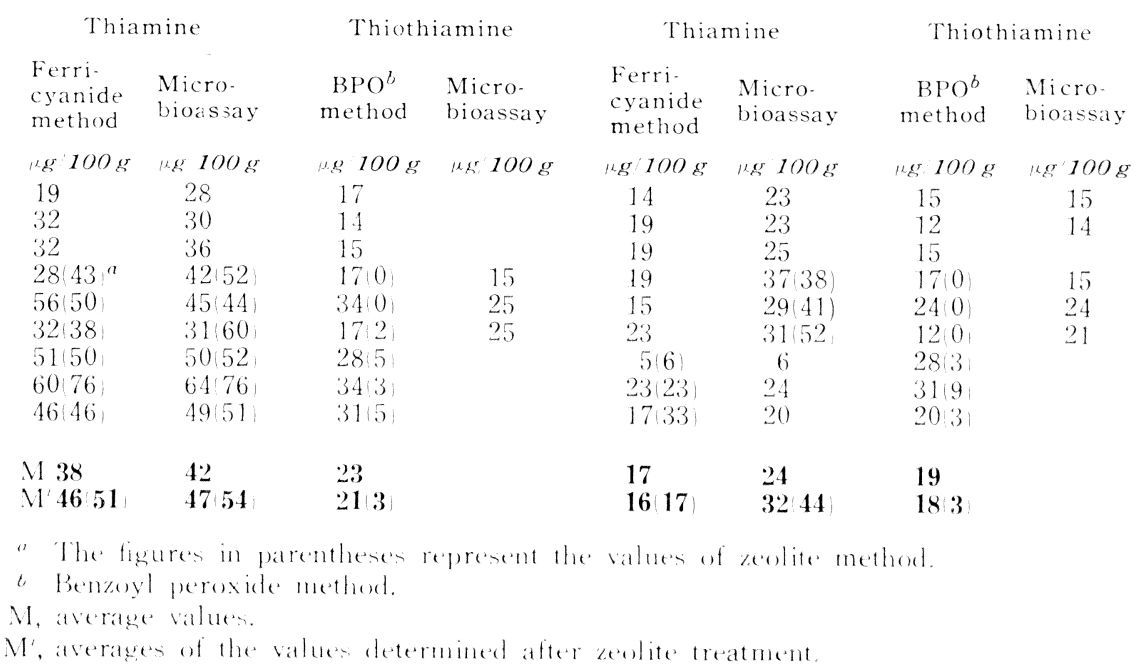


those obtained without zeolite treatment. This can be explained by the finding that thiothiamine is partially converted to thiamine in the course of zeolite treatment (6).

In order to test a question if the thiamine in onion homogenate may be converted into thiothiamine in the course of time, the following experiment was undertaken. $30-350 \mu \mathrm{g}$ thiamine per $100 \mathrm{~g}$ was added to the onion. A part was allowed to stand as it is and the other part was heated in a boiling water-bath for 10 minutes. Then each part was homogenized and allowed to stand at $\mathrm{pH} 6$ and $38^{\circ}$ for 24 hours. They were analyzed for thiothiamine by both benzoyl peroxide method and microbioassay. As shown in Table III, the conversion of thiamine into thiothiamine was not observed.

TABLE III

Change of Thiamine Added to Onion Extract

Thiamine was added to $100 \mathrm{~g}$ of onions followed by homogenization, then $A$ assayed immediately, $B$ after incubation at $38^{\circ}$ for 24 hours. Thiamine was determined microbiologically and thiothiamine by benzoyl peroxide method. The figures in parentheses represent the values determined after addition of thiamine, heating and homogenization.

\begin{tabular}{|c|c|c|c|c|c|}
\hline \multirow[b]{2}{*}{$\begin{array}{l}\text { Thiamine } \\
\text { added }\end{array}$} & \multicolumn{2}{|r|}{$A$} & \multicolumn{3}{|c|}{$B$} \\
\hline & Thiamine & $\begin{array}{l}\text { Thiothiamine } \\
\text { (BPO method) }\end{array}$ & Thiamine & $\begin{array}{l}\text { Thiothiamine } \\
\text { (micro- } \\
\text { bioassay) }\end{array}$ & $\begin{array}{l}\text { Thiothiamine } \\
\text { (BPO method) }\end{array}$ \\
\hline$\mu g$ & $\mu g$ & $\mu g$ & $\mu_{g}$ & $\mu g$ & $\mu g$ \\
\hline 350 & 391 (312) & $11(23)$ & $370(325)$ & $9(11)$ & $11(24)$ \\
\hline 300 & 271 (333) & $29(24)$ & $319(372)$ & $-2(16)$ & $23(32)$ \\
\hline 35 & $70(83)$ & 11 (17) & $74(78)$ & $5(12)$ & $31(23)$ \\
\hline 30 & $80(83)$ & 15 (12) & $34(42)$ & $3(9)$ & $13(17)$ \\
\hline
\end{tabular}

\section{Detection of Thiothiamine in Vegetables}

The test for thiothiamine was made in various vegetables by benzoyl peroxide method and in those positive for thiothiamine the determination of thiamine and

TABLE IV

Thiothiamine Contents in Vegetables Determined by Benzoyl Peroxide Method and Microbioassay

\begin{tabular}{lcccc}
\hline \multicolumn{1}{c}{ Sample } & $\begin{array}{c}\text { No. of } \\
\text { assay }\end{array}$ & $\begin{array}{c}\text { Thiamine } \\
\text { (microbioassay) }\end{array}$ & $\begin{array}{c}\text { Thiothiamine } \\
\text { (microbioassay) }\end{array}$ & $\begin{array}{c}\text { Thiothiamine } \\
\text { (BPO method) }\end{array}$ \\
\hline Udo (Aralia cordata) & 1 & $\mu g / 100 g$ & $\mu \mathrm{g} / \mathbf{1 0 0 g}$ & $\mu \mathrm{g} / \mathbf{1 0 0 g}$ \\
Lettuce & 1 & 59 & -1 & 6 \\
Sprouting bean & 1 & 102 & 0 & 0 \\
Parsley & 1 & 67 & -6 & 4 \\
Potato & 1 & 105 & 0 & 0 \\
Celery & 1 & 108 & -4 & 6 \\
Pea & 1 & 130 & -2 & 6 \\
Spinach & 1 & 66 & -35 & 0 \\
Stone-leek & 1 & 61 & -33 & 6 \\
Welsh onion & 4 & 44 & +23 & 41 \\
Scallion & 2 & 283 & -134 & 40 \\
Garlic & 6 & 55 & -25 & 29 \\
Cabbage & 4 & 101 & -40 & 76 \\
Sprouting cabbage & 4 & & & 6 \\
\hline
\end{tabular}


thiothiamine was made microbiologically. As summarized in Table IV, thiothiamine was negative by benzoyl peroxide method in the lettuce, parsley, celery and spinach, and almost negative in the pimiento, cucumber, tomato and pea. Thiothiamine was markedly detected by benzoyl peroxide method in cabbages, sprouting cabbages, Welsh onions, scallions and garlics and they were analyzed carefully for thiothia mine. In microbiological assay, thiothiamine was scarcely detected except for garlics and in many of them thiamine was decreased by sulfite treatment. Consequently, hydrogen peroxide was tried instead of sulfite.

\section{Oxidation of Thiothiamine with Hydrogen Peroxide}

Hydrogen peroxide solution containing $500 \mathrm{mg} \mathrm{H}_{2} \mathrm{O}_{2}$, was used as an oxidant instead of sulfurous acid water. Other procedures were the same as given above. First, cabbage was used as a sample and the recovery test was carried out with the results given in Table $\mathrm{V}$. The amounts of thiamine determined after $\mathrm{H}_{2} \mathrm{O}_{2}$ treatment following addition. of $50 \mu \mathrm{g}$ thiothiamine per $100 \mathrm{ml}$ were $50-90 \%$ of the values to be expected, and those following addition of $50 \mu \mathrm{g}$ thiamine per $100 \mathrm{ml}$ were $10-70 \%$ of those to be expected. These findings show that thiamine is partially destroyed by $\mathrm{H}_{2} \mathrm{O}_{2}$ treatment and the $\mathrm{H}_{2} \mathrm{O}_{2}$ treatment can not be a satis-

TABLE V

Treatment of Hydrogen Peroxide and Recovery Test of

Thiamine or Thiothiamine in Cabbage Extract

$\boldsymbol{A}$ The cold extract was directly treated, thiamine was determined microbiologically and thiothiamine by benzoyl peroxide method.

$B$ Thiothiamine or thiamine was added and after $\mathrm{H}_{2} \mathrm{O}_{2}$ treatment the extract was treated as above.

In the recovery tests, $50 \mu \mathrm{g}$ of thiothiamine or thiamine was added.

\begin{tabular}{|c|c|c|c|c|c|}
\hline \multicolumn{6}{|c|}{ Recovery test of thiothiamine } \\
\hline \multirow{2}{*}{ Sample } & \multicolumn{2}{|c|}{$A$} & \multicolumn{3}{|c|}{$B$ (Thiothiamine added) } \\
\hline & Thiamine & Thiothiamine & Thiamine & $\begin{array}{l}\text { Expected } \\
\text { value }\end{array}$ & Recovery \\
\hline & $\mu \mathrm{g} / 100 \mathrm{~g}$ & $\mu \mathrm{g} / 100 \mathrm{~g}$ & $\mu g / 100 \mathrm{~g}$ & $\mu \mathrm{g} / 100 \mathrm{~g}$ & per cent \\
\hline $\mathrm{D}$ & 26.5 & 40 & 105 & 132 & 80 \\
\hline $\mathrm{D}_{2}$ & 42.5 & 40 & 98 & 147 & 63 \\
\hline $\mathrm{E}_{1}$ & 56.0 & 40 & 115 & 161 & 72 \\
\hline $\mathrm{E}_{2}$ & 58.0 & 40 & 90 & 164 & 55 \\
\hline $\mathrm{G}^{4}$ interior & $73.5(63.6)$ & 11 & $75.6(64.5)$ & 86 & 88 \\
\hline $\mathrm{G}$ interior & $73.5(63.6)$ & 11 & $101.2(96.8)$ & 157 & 64 \\
\hline $\mathrm{G}$ exterior & $51.5(42.4)$ & 11 & $54(40)$ & 64 & 84 \\
\hline G exterior & $51.5(42.4)$ & 11 & $71.4(65.8)$ & 135 & 53 \\
\hline \multicolumn{6}{|c|}{ Recovery test of thiamine } \\
\hline \multirow{2}{*}{ Sample } & \multicolumn{2}{|c|}{$A$} & \multicolumn{3}{|c|}{$B$ (Thiamine added) } \\
\hline & Thiamine & Thiothiamine & Thiamine & $\begin{array}{l}\text { Expected } \\
\text { value }\end{array}$ & Recovery \\
\hline & $\mu g / 100 \mathrm{~g}$ & $\mu g / 100 g$ & $\mu \mathrm{g} / 100 \mathrm{~g}$ & $\mu g / 100 g$ & per cent \\
\hline $\mathrm{F}$ interior & 129 & 88 & 100.3 & 231 & 57 \\
\hline $\mathrm{F}$ interior & 129 & 88 & 94.5 & 281 & 34 \\
\hline F exterior & 53.5 & 55 & 36.6 & 118 & 31 \\
\hline F exterior & 53.5 & 55 & 16.0 & 168 & 9.5 \\
\hline $\mathrm{G}$ interior & 73.5 & 11 & $94 \quad(100)$ & 136 & 69 \\
\hline G exterior & 51,5 & 11 & $82.5(75.6)$ & 119 & 69 \\
\hline
\end{tabular}

The parenthesized figures indicate the values determined with ferricyanide. 


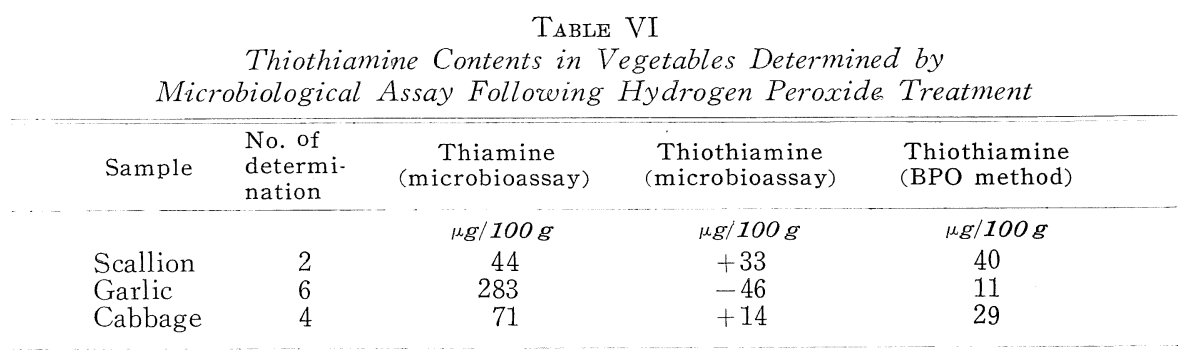

factory method for determining thiothiamine.

The results determined by this method in the scallion, cabbage and garlic are shown in Table VI. In scallions and garlics, formation of thiamine by $\mathrm{H}_{2} \mathrm{O}_{2}$ treatment was observed, showing the existence of thiothiamine.

\section{DISCUSSION}

The existence of thiothiamine in onions seems to be definite, since about the same values were obtained by three different methods, benzoyl peroxide method, $\mathrm{BrCN}$ oxidation method and microbioassay.

It was also detected in scallions by benzoyl peroxide method and microbioassay, but the latter value was lower than the former. In cabbages, thiothiamine was also detected by both benzoyl peroxide and $\mathrm{BrCN}$ methods. However, the value for thiamine was decreased by the microbioassay following sulfite treatment. Since thiamine alone was not decomposed by sulfite treatment, but destroyed after addition of cabbage extract, a thiamine-destroying factor or a factor capable of destroying thiamine in the existence of sulfite seems to be present in cabbages. In cabbages, a little thiothiamine was detected by converting thiothiamine into thiamine by $\mathrm{H}_{2} \mathrm{O}_{2}$ treatment. However, the recovery of thiamine or thiothiamine was very poor after adding thiothiamine or thiamine, possibly due to the decompasition of thiamine by $\mathrm{H}_{2} \mathrm{O}_{2}$ treatment. The existence of thiothiamine in cabbages seems to be certain, as thiothiamine is definitely detected by three methods, i.e., microbioassay following $\mathrm{H}_{2} \mathrm{O}_{2}$ treatment, benzoyl peroxide method and $\mathrm{BrCN}$ method. In garlics no increase of thiamine was detected by both sulfite and $\mathrm{H}_{2} \mathrm{O}_{2}$ treatments, but on the contrary the value fell. In case of garlics, however, detection of thiothiamine may be difficult owing to the formation of allithiamine and more detailed investigation is necessary.

Thiothiamine was detected by both chemical and microbiological methods in onions, cabbages and scallions. Thus the possibility of existence of thiothiamine in vegetables has been amply proved. However, alkylsulfide, alkyldisulfide and other sulfur compounds have been shown to be present in these vegetables and there is a possibility of producing thiothiamine from thiamine during homogenation. Yurugi (3) has reported that thiothiamine was formed from thiamine when the vitamin was allowed to react with the extract of onions, Welsh onions or chives at $\mathrm{pH} 8$. In the author's experiment, onions were extracted in an acidic solution and the thiamine added the to onion homogenate did not change into thiothiamine. Therefore, the thiothiamine detected can not have been formed from thiamine during the procedure. 


\section{SUMMARY}

For determination of thiothiamine in natural foodstuffs two chemical methods other than benzoyl peroxide method which had hitherto been used, have been described. One is an oxidation method by $\mathrm{BrCN}$ in an acidic medium and the other a microbiological method using L. fermenti, following conversion of thiothiamine into thiamine by sulfite. Applying these methods, thiothiamine contents in various vegetables were determined. Thiothiamine was detected in onions, Welsh onions, scallions, garlics, cabbages, sprouting cabbages by benzoyl peroxide method. In onions, thiothiamine was determined by benzoyl peroxide, $\mathrm{BrCN}$ and microbiological methods with the results agreeing fairly well one another. In scallions, thiothiamine was detected also microbiologically. However, the values were lower than those determined by benzoyl peroxide method, whereas in cabbages thiothiamine was not detected microbiologically. After converting thiothiamine into thiamine by $\mathrm{H}_{2} \mathrm{O}_{2}$ treatment, thiothiamine could be detected also in cabbages, but the recovery was poor, possibly due to the decomposition of thiamine by $\mathrm{H}_{2} \mathrm{O}_{2}$. The existence of thiothiamine in natural foodstuffs needs further investigations.

\section{ACKNOWLEDGEMENT}

The authors wish to express their gratitude to Prof. Chikataro Kawasaki, Pharmaceutical Department, Osaka University for his kind guidance and revision, to Assistant Prof. Eiichi Hiraoka for his helpful advice, and to Misses Katsuko Akagi, Teruko Fujii and Reiko Nakajima for their assistance.

\section{REFERENCES}

1. Kawasaki, C., Suhara, T., and Horio, T., Yakugaku Zasshi 78, 65 (1958).

2. Kawasaki, C.. and Horio, T. Vitamins 12, 183 (1957).

3. Yurugi, S., Yakugaku Zasshi 74, 506 (1954).

4. Kawasaki, C., and Horio, T., Vitamins 12, 228, 233 (1957).

5. Fujiwara, M., and Kitamura, M., Assay Methods of B Complex Vitamins (Japanese) p. 56, Kokumin Kagakusha, Kyoto (1949).

6. Kawasaki, C., and Horio, T., ibid. 14, 290 (1958). 